\title{
Stevens-Johnson Syndrome Induced by Mycoplasma Pneumoniae Infection
}

\author{
Dr. Thiago de Almeida Prado Naves Carneiro - DDS; MSc \& PhD \\ Post-Doctoral Research Fellow, Department of Occlusion, Fixed Prostheses, and Dental Materials, \\ School of Dentistry, Universidade Federal de Uberlândia, Uberlândia, Minas Gerais Brazil \\ Dra. Livia Bonjardim Lima - DDS; MSc \\ PhD Student, Department of Occlusion, Fixed Prostheses, and Dental Materials, School of Dentistry, \\ Universidade Federal de Uberlândia, Uberlândia, Minas Gerais Brazil \\ Dr.MaiolinoThomaz Fonseca Oliveira - DDS; MSc \& PhD \\ Oral and Maxillofacial Surgery Department, Federal University of Uberlândia, MG, Brazil \\ Dr. Antônio Francisco Durighetto Júnior - DDS; MSc \& PhD \\ Professor, Pitágoras School of Dentistry, Uberlândia, Minas Gerais, Brazil \\ Dr.Luiz Fernando Barbosa de Paulo - DDS; MSc \& PhD \\ Program of Specific Care of Oral Diseases, Stomatology Diagnosis Unit, HC, \\ Federal University of Uberlândia, Uberlândia, Minas Gerais, Brazil
}

\begin{abstract}
The mucocutaneous manifestations of Mycoplasma pneumoniae infection appear in approximately $20 \%$ of all the infections produced by this microorganism. Maculopapular rash and vesicular exanthemas are frequent manifestations that can constitute Erythema multiforme or more rarely, Stevens-Johnson syndrome. We describe the clinical evolution, diagnosis and treatment of two children with mucous and cutaneous manifestations associated to infection by Mycoplasma pneumoniae.
\end{abstract}

\section{CASE REPORTS}

Two boys with five and six years-old respectivelypresented with a 4-day history of non-productive cough, headache and fever, complaining of mouth soreness and painful lip lesions. Physical examination revealed conjunctivitis in both, buccal mucosa and lips showed painful ulcerative bleeding lesions covered with serofibrinous exudates. The younger patient presented a rash on the palms, soles of the feet, back, and scattered throughout the extremities (Figure 1). Genital mucosa was unremarkable and lung auscultation revealed minor crackles with a mild bilateral interstitial pattern on chest radiograph. The older patient developed urethral discharge and a small, non-painful ulcer on his glans penis (Figure 2). His lung auscultation revealed bilateral wheezing and fine end-inspiratory crepitations.

In both patients, laboratory examinations were significant for leukocytosis and a Mycoplasma pneumonia IgM positive by enzyme immunoassay. The remainder of the laboratory evaluation was normal including hematocrit, platelets, electrolytes, and Venereal Disease Research Laboratory (VDRL). Stevens Johnson syndrome secondary to Mycoplasma pneumoniae infection was diagnosed. The patients started intravenous azithromycin for a 5-day course. Adequate supportive care including wound care, fluid and electrolyte management, nutritional support and monitoring for superinfections was provided. Symptoms resolved completely within 2 weeks, and the patients are in good health after a six months follow-up.

The Stevens Johnson syndrome is a variant of erythema multiforme, a rare acute mucocutaneous condition caused by a hypersensitivity reaction. ${ }^{1}$ Skin, oral and genital mucosa, lips, and conjunctivae 


\section{Dr. Thiago de Almeida Prado Naves Carneiro et al.}

are particularly involved. ${ }^{1,2}$ Drugs and infections, most commonly Mycoplasmapneumoniae, are wellknown precipitating factors. ${ }^{1-3}$ Treatment remains supportive and symptomatic.

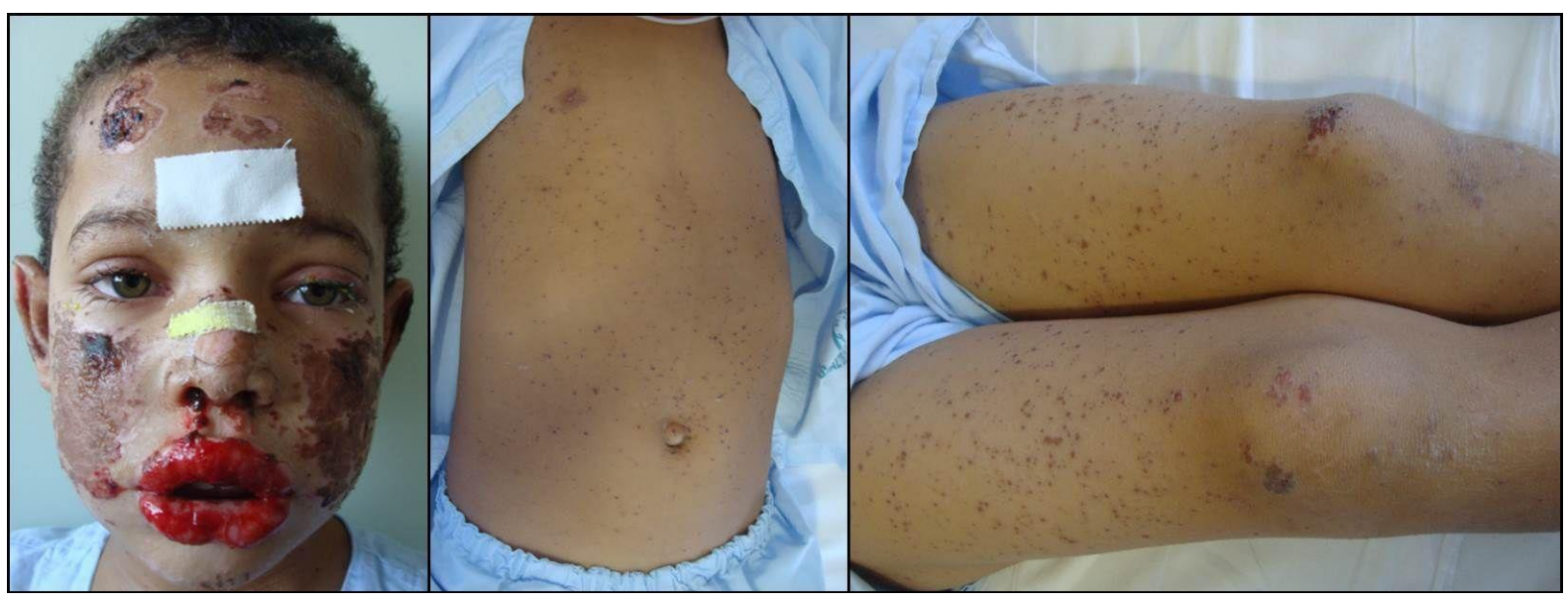

Figure 1. Physical aspects of 5 year-old boy. Skin rash and ulcerative bleeding lesions on the lip are noted.

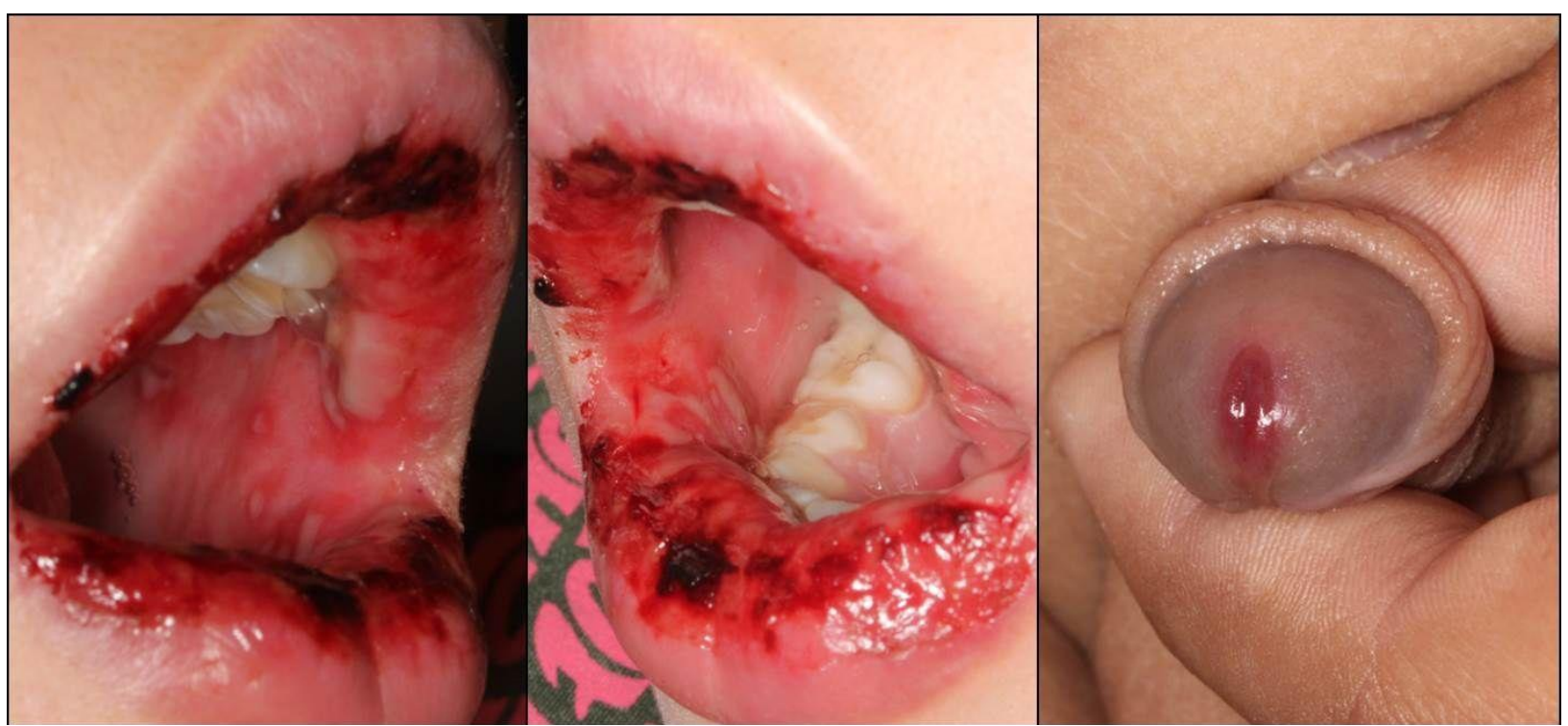

Figure 2. Physical aspects of 6 year-old boy. The vermillion of the lips was fissured, with serum, blood, and crust. Oral and genital mucosa was affected.

\section{REFERENCES}

[1] Sargenti Neto S, de Paulo LF, Rosa RR, DurighettoAF.(2013)Stevens-Johnson syndrome: an oral viewpoint. Int J PediatrOtorhinolaryngol, 77, 284-6.

[2] Vujic I, Shroff A, Grzelka M, Posch C, Monshi B, Sanlorenzo M, Ortiz-Urda S, Rappersberger K. (2014) Mycoplasma pneumoniae-associated mucositis - case report and systematic review of literature. J EurAcadDermatolVenereol, 17.

[3] Waites KB. New concepts of Mycoplasma pneumoniae infections in children. (2003) PediatrPulmonol, 36, 267-78. 